\section{Optimizing diagnostic biomarkers of iron deficiency anemia in community-dwelling Indian women and preschool children}

\author{
Giridhar Kanuri, ${ }^{1,2}$ Deepti Chichula, ${ }^{1}$ Ritica Sawhney, ${ }^{1}$ Kevin Kuriakose,${ }^{1}$ \\ Sherwin De'Souza, ${ }^{1}$ Faye Pais, ${ }^{1}$ Karthika Arumugam ${ }^{1}$ and Arun S. Shet ${ }^{1,3}$ \\ ${ }^{1}$ Wellcome Trust- DBT Hematology Research Unit, St. Johns Research Institute, \\ Bangalore, Karnataka, India; '2Department of Biotechnology, KLEF, Greenfields, \\ Vaddeswaram, Andhra Pradesh, India and ${ }^{3}$ National Heart Lung and Blood Institute, \\ National Institutes of Health, Bethesda, MD, USA
}

\section{ABSTRACT}

T he detection of iron deficiency anemia is challenged by the paucity of diagnostic tests demonstrating high sensitivity and specificity. Using two biomarkers, zinc-protoporphyrin/heme and hepcidin, we established the diagnostic cut-off values for iron deficiency anemia in preschool children and women. We randomly selected non-anemic individuals $(\mathrm{n}=190$; women $=90$, children $=100)$ and individuals with iron deficiency anemia $(n=200$; women $=100$, children $=100)$ from a preexisting cohort of healthy preschool children and their mothers. The diagnostic performance of these biomarkers was estimated by analyzing receiver operating characteristic curves. Diagnostic cut-offs with a high predictive value for iron deficiency anemia were selected. Median zinc-protoporphyrin/heme and hepcidin values in non-anemic children were 49 $\mu \mathrm{mol} / \mathrm{mol}$ heme and $42 \mathrm{ng} / \mathrm{mL}$, respectively, and in non-anemic women these values were $66 \mu \mathrm{mol} / \mathrm{mol}$ heme and $17.7 \mathrm{ng} / \mathrm{mL}$, respectively. Children and women with iron deficiency anemia had higher zinc-protoporphyrin/heme ratios (children=151 $\mu \mathrm{mol} / \mathrm{mol}$ heme and women=155 $\mu \mathrm{mol} / \mathrm{mol}$ heme) and lower hepcidin levels (children $=1.2 \mathrm{ng} / \mathrm{mL}$ and women=0.6ng $/ \mathrm{mL}$ ). A zinc-protoporphyrin/ heme ratio cut-off $>90 \mu$ mole/mole heme in children and $>107$ $\mu \mathrm{mole} / \mathrm{mole}$ heme in women was associated with a high diagnostic likelihood for iron deficiency anemia (children, likelihood ratio=20.2: women, likelihood ratio=10.8). Hepcidin cut-off values of $\leq 6.8 \mathrm{ng} / \mathrm{mL}$ in children and $\leq 4.5 \mathrm{ng} / \mathrm{mL}$ in women were associated with a high diagnostic likelihood for iron deficiency anemia (children, likelihood ratio=14.3: women, likelihood ratio=16.2). The reference ranges and cut-off values identified in this study provide clinicians with guidance for applying these tests to detect iron deficiency anemia. Erythrocyte zinc-protoporphyrin/heme ratio is a valid point-of-care biomarker to diagnose iron deficiency anemia.

\section{Introduction}

Iron deficiency anemia (IDA) is the leading cause of anemia worldwide ${ }^{1}$ with well established guidelines for diagnosis and treatment., ${ }^{2,3}$ Typically, the diagnosis of IDA is made when the plasma hemoglobin $(\mathrm{Hb})$ falls below normal $(<11.0 \mathrm{~g} / \mathrm{dL}$ in children and $<12 \mathrm{~g} / \mathrm{dL}$ in women) and the serum ferritin is $<12 \mu \mathrm{g} / \mathrm{L}{ }^{4}{ }^{4}$ Unfortunately, the frequent coexistence of inflammation/infection confounds serum ferritin, which is an acute phase protein, mandating the performance of additional tests e.g., C-reactive protein (CRP) and serum transferrin receptor (sTfR). As a result, the diagnosis of IDA often requires a battery of diagnostic tests, trained technicians, and the use of expensive laboratory equipment, which increases costs and delays results. Clearly, developing biomarkers that quickly, easily and reliably detect IDA would be beneficial.

One such biomarker, zinc-protoporphyrin (ZPP), is formed in erythrocytes during iron-deficient erythropoiesis when the protoporphyrin ring incorporates an atom of zinc rather than iron. The ratio of zinc-protoporphyrin/heme ( $\mathrm{ZPP} / \mathrm{H})$ can
Haematologica 2018

Volume 103(12):1991-1996

\section{Correspondence:}

arun.shet@nih.gov

Received: March 13, 2018.

Accepted: August 6, 2018.

Pre-published: August 9, 2018.

doi:10.3324/haematol.2018.193243

Check the online version for the most updated information on this article, online supplements, and information on authorship \& disclosures: www.haematologica.org/content/103/12/1991

(C)2018 Ferrata Storti Foundation

Material published in Haematologica is covered by copyright. All rights are reserved to the Ferrata Storti Foundation. Use of published material is allowed under the following terms and conditions:

https://creativecommons.org/licenses/by-nc/4.0/legalcode. Copies of published material are allowed for personal or internal use. Sharing published material for non-commercial purposes is subject to the following conditions:

https://creativecommons.org/licenses/by-nc/4.0/legalcode, sect. 3. Reproducing and sharing published material for commercial purposes is not allowed without permission in writing from the publisher. 
Table 1. Demographic, hematological and biochemical parameters of study participants.

\begin{tabular}{|c|c|c|c|c|}
\hline & & & Iron de & emia (IDA) \\
\hline & $\begin{array}{l}\text { Women } \\
(n=90)\end{array}$ & $\begin{array}{l}\text { Children } \\
(n=100)\end{array}$ & $\begin{array}{l}\text { Women } \\
(n=100)\end{array}$ & $\begin{array}{l}\text { Children } \\
n=100 \text { ) }\end{array}$ \\
\hline Age \pm SD & $26 \pm 3.7$ & $3.7 \pm 0.9$ & $25 \pm 3.8$ & $2.4 \pm 0.8^{\mathrm{a}}$ \\
\hline Sex M:F & na & $49: 51$ & na & $56: 44$ \\
\hline Hemoglobin $\pm \mathrm{SD}(\mathrm{g} / \mathrm{dl})$ & $13.2 \pm 0.7$ & $11.9 \pm 0.6$ & $10 \pm 1.2^{\mathrm{a}}$ & $9.6 \pm 0.8^{\mathrm{a}}$ \\
\hline $\mathrm{MCV} \pm \mathrm{SD}(\mathrm{fL})$ & $86 \pm 4.5$ & $77 \pm 3.7$ & $74 \pm 7.6^{\mathrm{a}}$ & $65 \pm 5.9^{\mathrm{a}}$ \\
\hline $\mathrm{WBC} \pm \mathrm{SD} \times 10^{3} / \mu \mathrm{L}$ & $8.7 \pm 2.0$ & $9.8 \pm 2.4$ & $7.8 \pm 2.0$ & $10.3 \pm 2.8$ \\
\hline Platelet count \pm SD x $10^{5} / \mu \mathrm{L}$ & $3 \pm 0.7$ & $3.9 \pm 1$ & $3.4 \pm 0.7$ & $4.6 \pm 1.2$ \\
\hline & & Bioc & rameters & \\
\hline Serum Ferritin*(ng/mL) & $39(33,48)$ & $35(32,45)$ & $3.7^{\mathrm{a}}(2.9,5.3)$ & $3.8^{\mathrm{a}}(2.6,5.1)$ \\
\hline Serum sTfR* (mg/L) & $1.3(1.1,1.5)$ & $1.7(1.5,2.0)$ & $3^{\mathrm{a}}(2.2,4.0)$ & $3.9^{a}(3,5.1)$ \\
\hline sTfR/logferritin index & $0.8(0.7,0.9)$ & $1.1(0.9,1.2)$ & $5.1^{\mathrm{a}}(3.5,8)$ & $6.9^{\mathrm{a}}(4.5,11.2)$ \\
\hline CRP* (mg/L) & $1.4(0.4,3.4)$ & $1.1(0.4,2.2)$ & $0.6^{\mathrm{a}}(0.1,2)$ & $0.5^{\mathrm{a}}(0.06,1.6)$ \\
\hline & & Biomarkers & & \\
\hline ZPP/H* ( mol/mol heme) & $66(53,83)$ & $49(39,60)$ & $155^{\mathrm{a}}(101,243)$ & $151^{\mathrm{a}}(104,263)$ \\
\hline Hepcidin* (ng/mL) & $17.7(9,38)$ & $42.6(25,62)$ & $0.6^{\mathrm{a}}(0.2,1.3)$ & $1.2^{\mathrm{a}}(0.5,3.6)$ \\
\hline
\end{tabular}

*Data represented as median (inter quartile range). ${ }^{a}<0.05$ compared with the appropriate non-anemic control group. SD: standard deviation; MCV: mean corpuscular volume; WBC: white blood cells; Stfr: serum transferrin receptor; CRP: C-reactive protein; ZPP/H: zinc protoporphyrin/heme.

be determined rapidly at the point-of-care (POC) by a hematofluorometer., ${ }^{5,6}$ Serum hepcidin, a key regulator of iron homeostasis, is an important biomarker because its levels determine how well oral iron is absorbed, with low hepcidin levels indicating both a requirement for iron and an ability to utilize it if provided. ${ }^{7,8}$

Although ZPP/H reference values are available for iron deficient pregnant women ${ }^{5}$ and children, ${ }^{6}$ cut-off values that establish a diagnosis of IDA with acceptable sensitivity and specificity are lacking. Moreover, reference ranges for hepcidin in healthy rural Indian women and children are not defined. Indian women and preschool age children account for one-third of the global burden of anemia., Establishing reference ranges for these two biomarkers among healthy individuals and determining cut-off values for the diagnosis of IDA could facilitate their use and the development of novel POC assays. Therefore, we sought to define the median erythrocyte ZPP/H and serum hepcidin levels and select optimal cut-off values for the diagnosis of IDA in healthy rural preschool children and their mothers.

\section{Methods}

\section{Definition of study groups and sample selection}

In total, there were 2227 samples that were divided into three groups (non-anemic individuals, and those with IDA or iron deficiency without anemia) (Figure 1). Women and children with anemia (WHO recommended $\mathrm{Hb}$ concentrations anemia $<11 \mathrm{~g} / \mathrm{dL}$ for children and $<12 \mathrm{~g} / \mathrm{dL}$ for women ${ }^{2}$ ) with absent body iron stores (serum ferritin $<12 \mathrm{ng} / \mathrm{mL}^{4}$ ), were categorized into the IDA group (women $n=334$ and children $n=560$ ). Women and children without anemia ( $\mathrm{Hb} \geq 11 \mathrm{~g} / \mathrm{dL}$ for children and $\geq 12 \mathrm{~g} / \mathrm{dL}$ for women) having normal iron stores (serum ferritin $\geq 30 \mathrm{ng} / \mathrm{mL}$ ) were categorized into the non-anemic group (women $\mathrm{n}=99$ and children $\mathrm{n}=173$ ). Women and children with normal $\mathrm{Hb}$ but low body iron stores (ferritin $<30 \mathrm{ng} / \mathrm{mL}$ ) were categorized as having iron deficiency without anemia and excluded from the study $(n=1061)$. Subsequently, using a computerized random number generator we selected 200 samples from the IDA group (100 each from both women and children) and 190 samples from the non-anemic group (Children=100; Women=90) and performed biomarker measurements. ${ }^{10}$ Using a sTfR/log ferritin index $>2$, we diagnosed nutritional IDA without coexisting anemia of inflammation. ${ }^{11,12}$ Study location, sample size, and processing are detailed in Online Supplementary Methods.

\section{Ethics}

The study was approved by the St. Johns National Academy of Health Sciences Institutional Ethical Committee (IEC115/2012, IEC119/2013, and IEC121/2015).

\section{Biomarkers, ferritin, sTfR and Inflammation assays}

Serum hepcidin was quantified using an enzyme-linked immunosorbent assay (Peninsula Labs, San Carlos, CA, USA). The hepcidin concentration was extrapolated from a standard curve generated by four parametric logistic regression in accordance with manufacturer instructions. $\mathrm{ZPP} / \mathrm{H}$ was measured using a hematofluorometer (Aviv Biomedical, Lakewood, NJ, USA) calibrated with commercially available standards. Samples were measured in triplicate and the average value obtained was expressed in umole/mole heme. Due to a high baseline prevalence of inflammation in this population, we measured sTfR, an indicator of iron status that is not affected by the acute phase response. We calculated the sTfR/log ferritin index to accurately distinguish IDA from anemia of inflammation. ${ }^{13}$ Serum ferritin and sTfR levels were both measured by paramagnetic particle chemiluminescent immunoassay 


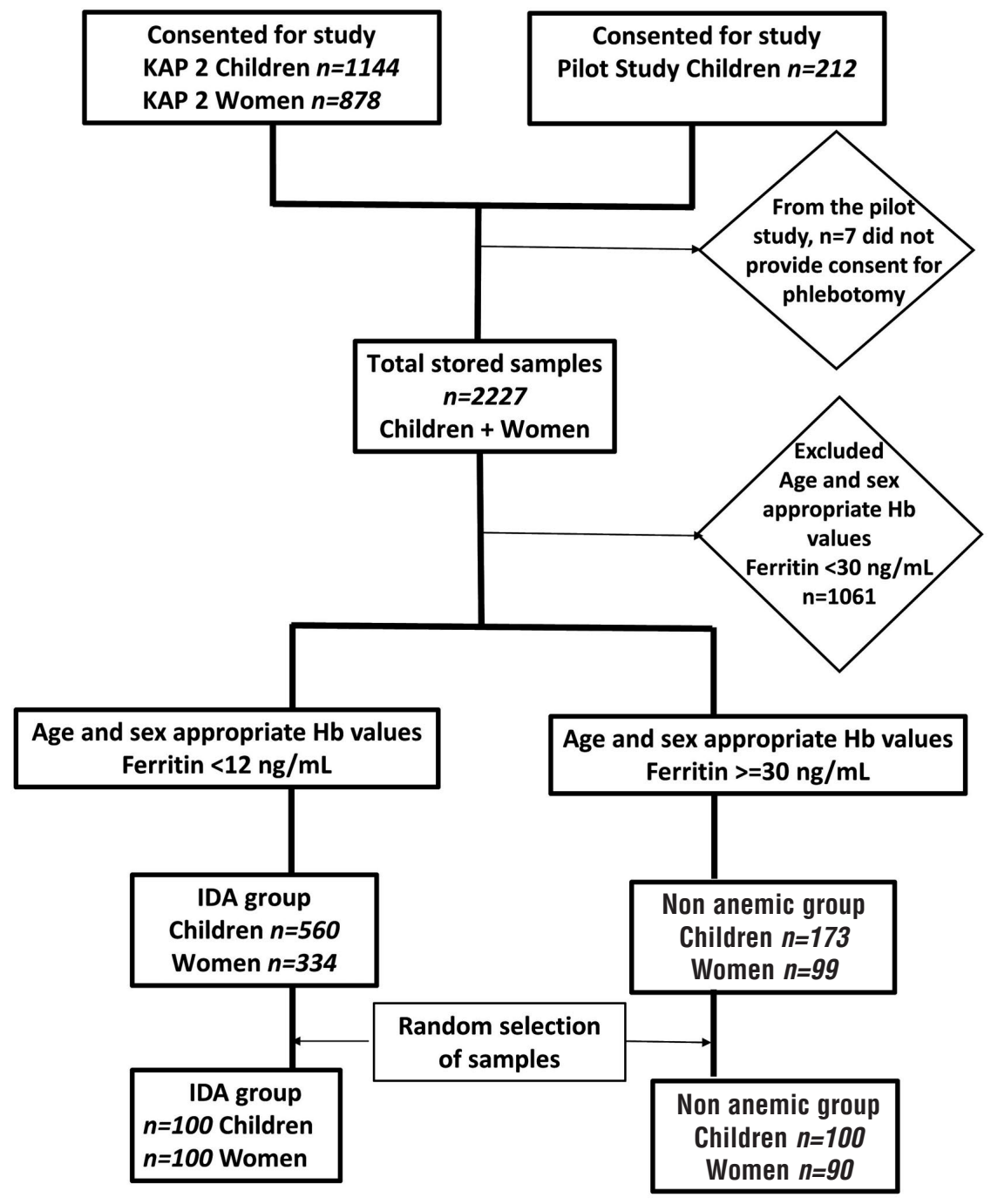

Figure 1. Flow diagram of participants and categorization of study groups. Schematic representation of the study design and sample selection. Using age and gender-adjusted WHO definitions for $\mathrm{Hb}$ and serum ferritin, samples were divided into a non-anemic group and a group with iron deficiency anemia. Those individuals with normal $\mathrm{Hb}$ values but low serum ferritin were defined as having iron deficiency and excluded. Using a computer random number generator, 200 samples from the iron deficiency anemia group (children $=100$; women $=$ $100)$ and 190 samples from the non-anemic group (Children $=100$; Women $=90$ ) were randomly selected for biomarker measurements. IDA: iron deficiency anemia; $\mathrm{Hb}$ : hemoglobin.

(Access 2, Beckman Coulter). Serum high sensitivity (hs)CRP, a biochemical measure of inflammation, was determined by quantitative sandwich enzyme-linked immunosorbent assay ([ELISA] R\&D systems, Minneapolis, MN, USA).

\section{Statistical analysis}

Variables were aggregated into mean \pm SD (continuous variables with a Gaussian distribution, t-test for departure from no difference) and median with the interquartile range ([IOR] continuous variables with non-Gaussian distribution, Mann-Whitney test for departure from no difference).

To determine ZPP/H and serum hepcidin cut-off values for IDA diagnosis, we used receiver operating characteristic (ROC) curves with IDA defined as $\mathrm{Hb}$ below the normal range combined with serum ferritin $<12 \mathrm{ng} / \mathrm{mL}$. Youden index (J=sensitivity+specificity-1) and likelihood ratios $[\mathrm{LR}+=$ sensitivity/(1-specificity)] [LR-=(1-sensitivity)/specificity] were calculated for each individual cut-off value of $\mathrm{ZPP} / \mathrm{H}$ and hepcidin. This iterative process began with the selection of the highest Youden indices corresponding with the highest positive likelihood ratio for IDA. ${ }^{14}$ The conventional threshold of $<0.05$ was used for statements about statistical significance. All statistical analyses were done using SPSS 16.0 software (SPSS Inc., Chicago, IL, USA) and ROC curves were performed using MedCalc software (MedCalc, Ostend, Belgium).

\section{Results}

Comparison of baseline characteristics between the two groups (non-anemic and IDA) for children and women are presented as mean \pm SD for variables with a normal distribution and as the median \pm interquartile range for variables that are not normally distributed. Age, gender, hematological and biochemical parameters are presented in Table 1 and ROC estimates, Youden indices, and likelihood ratios are presented in Table 2 .

\section{Baseline characteristics of the anemic and non-anemic groups}

Non-anemic children were slightly older than children with IDA (3.7 \pm 0.9 vs. $2.4 \pm 0.8$ years) (Table 1 ) while the ages of non-anemic women and women with IDA did not differ (26 \pm 3.7 years vs. $25 \pm 3.8$ years) (Table 1$)$. Women and children with IDA had significantly lower mean $\mathrm{Hb}$ 
Table 2. Properties of selected hepcidin and ZPP/H cut-off values for iron deficiency anemia diagnosis.

\begin{tabular}{|c|c|c|c|c|c|c|c|c|c|c|}
\hline Study group & $\begin{array}{l}\text { Biomarker } \\
\text { Cut-off Value }\end{array}$ & Sensitivity & $95 \%$ CI & Specificity & $95 \%$ CI & $\mathbf{L R}^{+}$ & $\mathbf{L R}^{-}$ & $\begin{array}{l}\text { Youden } \\
\text { Index }\end{array}$ & $\begin{array}{l}\text { Positive } \\
\text { Predictive }\end{array}$ & $\begin{array}{l}\text { Negative } \\
\text { Predictive }\end{array}$ \\
\hline & $\begin{array}{c}\mathrm{ZPP} / \mathrm{H} \\
\mu \mathrm{mol} / \mathrm{mol} \text { heme }\end{array}$ & & & & & & & & & \\
\hline Children & $>90$ & 81 & $71.9-88.2$ & 96 & $90.1-98.9$ & 20.25 & 0.2 & 0.77 & 95.29 & 83.48 \\
\hline Women & $\begin{array}{c}>107 \\
\text { Hepcidin ng/mL }\end{array}$ & 73 & $63.2-81.4$ & 93 & $85.9-97.5$ & 10.83 & 0.29 & 0.66 & 91.25 & 77.5 \\
\hline Children & $\leq 6.85$ & 86 & 77.6 - 92.1 & 94 & $87.4-97.8$ & 14.33 & 0.15 & 0.80 & 93.48 & 85.45 \\
\hline Women & $\leq 4.52$ & 90 & $82.4-95.1$ & 94 & $87.5-98.2$ & 16.2 & 0.11 & 0.84 & 93.75 & 90.38 \\
\hline
\end{tabular}

CI: confidence interval; +LR: positive likelihood ratio; -LR: negative likelihood ratio; ZPP/H: zinc protoporphyrin/heme.

A

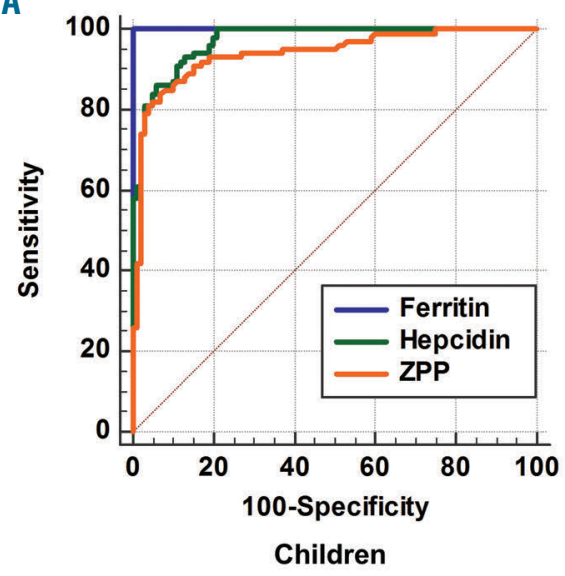

B

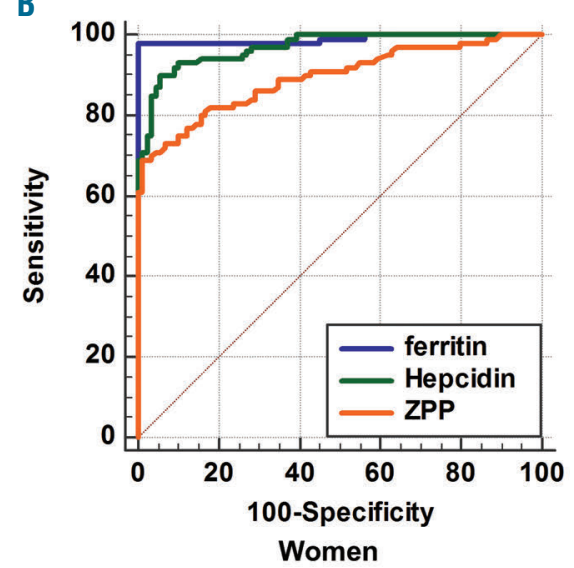

Figure 2. Receiver operating characteristic curves for ferritin, hepcidin and $\mathrm{ZPP} / \mathrm{H}$. Pairwise comparison of area under ROC curves of hepcidin and $\mathrm{ZPP} / \mathrm{H}$ with ferritin as a gold standard for IDA diagnosis in (A) children and in (B) women. As noted, the AUC is similar between the gold standard (ferritin) and either hepcidin or $\mathrm{ZPP} / \mathrm{H}$ indicating the inherent ability of these two biomarker tests to discriminate between the non-anemic and IDA groups. ZPP: zinc protoporphyrin.
(Children: $9.6 \pm 0.8 \mathrm{~g} / \mathrm{dL}$ vs. $11.9 \pm 0.6 \mathrm{~g} / \mathrm{dL}$; Women: $10 \pm$ $1.2 \mathrm{~g} / \mathrm{dL}$ vs. $13.2 \pm 0.7 \mathrm{~g} / \mathrm{dL})$, mean corpuscular volume (Children: 65 vs. 77fl, Women: 74 vs. 86fl) and median ferritin (Children: 3.8 vs. 35ng/mL, Women: 3.7 vs. 39ng/mL) compared with non-anemic women and children, respectively (Table 1).

There were no differences in white blood cell and platelet counts between the two study groups (Table 1). Serum CRP values were low in both study groups (Table 1). As expected, sTfR was significantly higher in children and women with IDA compared with their non-anemic counterparts (Children: 3.9 vs. $1.7 \mathrm{mg} / \mathrm{L}$; Mothers: 3 vs. $1.3 \mathrm{mg} / \mathrm{L})$ (Table 1). Moreover, sTfR/log ferritin index values $>2$ in women and children with IDA confirmed a diagnosis of IDA and ruled out coexisting anemia of inflammation (Table 1).

\section{Erythrocyte ZPP/H and serum hepcidin values in anemic and non-anemic groups}

The median ZPP/H in children and women with IDA was higher when compared with their non-anemic counterparts (children: $151 \mu \mathrm{mol} / \mathrm{mol}$ heme [IOR: 104, 263] vs. $49 \mu \mathrm{mol} / \mathrm{mol}$ heme [IOR: 39, 60] and women: 155 $\mu \mathrm{mol} / \mathrm{mol}$ heme [IOR: 101, 243] vs. $66 \mu \mathrm{mol} / \mathrm{mol}$ heme [IOR: 53, 83], $P<0.001$ for both) (Table 1). Median hepcidin concentration was markedly higher in non-anemic children and women when compared with their counterparts who had IDA (children: 42ng/mL [IOR: 25, 62] vs.
$1.2 \mathrm{ng} / \mathrm{mL}$ [IOR: $0.5,3.6]$ and women: $17.7 \mathrm{ng} / \mathrm{mL}$ [IOR: 9 , 38] vs. $0.6 \mathrm{ng} / \mathrm{mL}$ [IOR: $0.2,1.3], P<0.05$ for both) (Table 1 ).

\section{Diagnostic cut-off for erythrocyte ZPP/H}

$\mathrm{ZPP} / \mathrm{H}>90 \mu \mathrm{mole} / \mathrm{mole}$ heme resulted in IDA diagnosis in children with $81 \%$ sensitivity and $96 \%$ specificity (Table 2). This cut-off had a positive likelihood ratio of 20.25 and a positive predictive value of $95.2 \%$ (Table 2 ). In women, a higher $\mathrm{ZPP} / \mathrm{H}>107 \mu$ mole/mole heme resulted in IDA diagnosis with $73 \%$ sensitivity and $93 \%$ specificity. This cut-off in women yielded a positive likelihood ratio of 10.8 and a positive predictive value of $91.2 \%$ (Table 2). ROC curves for $\mathrm{ZPP} / \mathrm{H}$ to diagnose IDA revealed an area under the curve (AUC) $)^{\text {ROC }}$ of 0.94 in children (Figure $2 \mathrm{~A})$ and $0.89(P<0.0001)$ in women (Figure $2 \mathrm{~B})$.

\section{Diagnostic cut-off for serum hepcidin}

Serum hepcidin value $\leq 6.85 \mathrm{ng} / \mathrm{mL}$ yielded an IDA diagnosis in children with $86 \%$ sensitivity and $94 \%$ specificity (Table 2). This cut-off had a likelihood ratio of 14.3 with a positive predictive value of $93.4 \%$ (Table 2 ). In women, a hepcidin value of $\leq 4.5 \mathrm{ng} / \mathrm{mL}$ resulted in an IDA diagnosis with $90 \%$ sensitivity and $94 \%$ specificity (Table 2). This cut-off corresponded with a likelihood ratio of 16.2 and a positive predictive value of $93.7 \%$. ROC curves for hepcidin to diagnose IDA revealed an AUC ${ }^{\mathrm{ROC}}$ of 0.97 in children (Figure 2A) and 0.96 $(P<0.0001)$ in women (Figure $2 \mathrm{~B})$. 


\section{Discussion}

In this study of healthy rural community-dwelling nonanemic Indian women and children and their counterparts with biochemically defined IDA, we 1) report the median values for the iron biomarkers erythrocyte $\mathrm{ZPP} / \mathrm{H}$ and serum hepcidin, 2) analyze ROC curves for erythrocyte $\mathrm{ZPP} / \mathrm{H}$ and serum hepcidin, and 3) define the ZPP/H ratio and serum hepcidin cut-off values for IDA diagnosis and estimate the post-test probability of IDA for these cut-off values. Overall, these findings demonstrate the utility of erythrocyte ZPP/H as a POC biomarker for IDA diagnosis, particularly in women and children from low-middle income settings.

We found similar median ZPP/H levels in non-anemic children to those reported previously (47.5 and $58 \mu \mathrm{mol} / \mathrm{mol}$ heme). ${ }^{15,16}$ Although evaluated systematically in children and non-anemic pregnant women with iron deficiency, ${ }^{5,17} \mathrm{ZPP} / \mathrm{H}$ levels have not been studied either in women or preschool children using rigorous criteria for nutritional IDA. Only one large Indian study of tribal adults and children ( $<18$ years) previously used ZPP/H to detect IDA in a subset $(n=100)$ of anemic individuals (mean $\mathrm{Hb}$ 8.4) with normal $\mathrm{Hb}$ phenotype. ${ }^{18}$ The authors reported a higher mean $\mathrm{ZPP} / \mathrm{H}$ value $(214.9 \pm 120.1)$ than in our study. This discrepancy may be explained by either the difference in the two study populations (severity of anemia or undetected $\mathrm{Hb}$ disorders) or methodological differences (i.e., whole blood vs. washed erythrocytes). ${ }^{19}$ The median ZPP/H ratios reported in our study probably reflect values encountered in healthy women and children residing in rural Indian communities.

Serum hepcidin values in non-anemic children in our study are concordant with reports in European children, ${ }^{20,21}$ but higher than values reported in Asian ${ }^{22}$ and African children. ${ }^{23,24}$ The inclusion of $<12$-month-old non-anemic children in the latter studies explain these differences, since hepcidin concentrations are decreased between three and six months of age ${ }^{24}$ Children with IDA in our study had serum hepcidin levels comparable with those reported in anemic children from $\mathrm{Asia}^{25}$ and Africa. ${ }^{23}$ Non-anemic women in our study had variable levels compared with those previously reported in European studies, ${ }^{26,27}$ discrepancies that are possibly explained by socioeconomic and dietary differences between these populations. Some of the inter-study variability is also possibly attributable to differences in the methodological assays used to estimate hepcidin. ${ }^{28}$ Women with IDA in our study had very low median hepcidin levels concordant with previously published studies. ${ }^{29}$

Using ROC analysis, we selected cut-off values for $\mathrm{ZPP} / \mathrm{H}$ that detected IDA in both women and children with $>90 \%$ specificity. Cut-off values selected in recent studies were lower ( $>40 \mu \mathrm{mole} / \mathrm{mole}^{30,31}$ heme and $>70$ $\left.\mu \mathrm{mol} / \mathrm{mole} \mathrm{heme}^{6}\right)$ and lacked specificity $(56 \%$ and $60 \%$, respectively), perhaps because they were selected to detect iron deficiency, not IDA. Another recent study utilized a ZPP/H cut-off value of $70 \mu \mathrm{mole} / \mathrm{mole}$ to diagnose IDA in a pediatric population, but this value had a low specificity $(75 \%))^{32}$ The large Indian study referenced previously used a cut-off value of $>80 \mu \mathrm{mole} / \mathrm{mole}$ heme to define IDA in a mixed population of healthy individuals and those with sickle cell trait or sickle cell anemia. ${ }^{18}$ The scientific rationale for this cut-off value and the validity of $\mathrm{ZPP} / \mathrm{H}$ as a stand-alone diagnostic assay for IDA in individuals with sickle cell anemia, and possibly $\alpha$-thalassaemia, ${ }^{33}$ is uncertain. In contrast, our study used rigorous biochemical criteria to define IDA in a representative sample of healthy community-dwelling women and children. Consequently, this is the first study to demonstrate the utility of ZPP/H as a biomarker of IDA and define cutoff values with which to establish an IDA diagnosis in healthy rural women and children.

The hepcidin cut-off values selected to diagnose IDA in children in our study were higher than those selected previously in Korean children ( $\leq 6.85 \mathrm{ng} / \mathrm{mL} v s . \leq 2.735 \mathrm{ng} / \mathrm{mL})$ and yielded higher AUCs (0.97vs. 0.90) ${ }^{25}$ The higher AUC value indicates a better discriminative power of hepcidin in detecting IDA. However, these cut-off values were similar to values that detect IDA in six to 60-month-old Gambian and Tanzanian children (5 and $8 \mathrm{ng} / \mathrm{ml}$, respectively).

The proposed cut-off values, with their high sensitivity and specificity, increase the probability of a diagnosis of IDA. However, we also determined the predictive values of these tests by estimating their likelihood ratios. The likelihood ratio indicates how many times more likely a particular test result is, in a patient with that particular condition, with a likelihood (LR) ratio value $>10$ providing robust diagnostic evidence. ${ }^{34}$ Assuming a pre-test probability of IDA of $50 \%$ in any given population, the selected $\mathrm{ZPP} / \mathrm{H}$ and hepcidin cut-off values had likelihood ratios of $\sim 10$, which according to the Fagan nomogram corresponded with a $90 \%$ post-test probability of having an IDA diagnosis. ${ }^{35}$ Thus, even in populations with lower pre-test probabilities of having IDA, these diagnostic cutoffs are valid.

Measuring erythrocyte $\mathrm{ZPP} / \mathrm{H}$ is procedurally simple, technically feasible by field health workers possessing $<12^{\text {th }}$-grade education, and could provide rapid results at the primary health center. Rapid diagnosis would facilitate therapeutic decision-making in a single visit and favor patient convenience, an important consideration in lowmiddle income settings. Although not a prior study objective, informal assay cost estimates in our laboratory indicate that $\mathrm{ZPP} / \mathrm{H}$ measurement is cheaper than hepcidin. Thus, our findings suggest that $\mathrm{ZPP} / \mathrm{H}$ has greater utility as a POC diagnostic test to detect IDA in women and children. Although hepcidin is extremely useful in predicting iron absorption and incorporation into erythrocytes, potential limitations of its use in this setting include higher costs, lack of hepcidin standardization and the requirement to convert the immunological assay into a POC assay. ${ }^{36}$

The strengths of this study are its inclusion of a large representative sample of healthy community dwelling women and children, a random selection of blood samples for biomarker measurements, and rigorous definition of IDA using multiple biomarkers. ${ }^{4,7}$ Using a combination of low $\mathrm{Hb}$ with ferritin as a gold standard for IDA instead of bone marrow aspiration with perls staining raises potential concerns regarding diagnostic accuracy. Reassurance against this concern is provided by the sTfR/log ferritin index $>2$ and near normalization of $\mathrm{Hb}$ in response to iron therapy in children with IDA after six months treatment (baseline $\mathrm{Hb}$ for children in the IDA group $=9.6 \pm 0.8 \mathrm{~g} / \mathrm{dL}$; six-month post-treatment $\mathrm{Hb}=10.5 \pm 1.3 \mathrm{~g} / \mathrm{dL}$ ). Finally, estimates of the diagnostic accuracy for the proposed cutoff values highlight the clinical applicability of these find- 
ings for IDA diagnosis. ${ }^{38}$ The results of this study are generalizable to women and children from similar agrarian parts of India and possibly to other similar low-middle income settings around the world.

In conclusion, the findings of this study provide a scientific rationale for the use of $\mathrm{ZPP} / \mathrm{H}$ as a POC biomarker to establish the diagnosis of IDA in women and children from low-middle income settings. The diagnostic cut-off values and their accompanying likelihood ratio's provide clinicians with guidance for using these biomarkers to diagnose IDA.

\section{Acknowledgments}

The study samples were a part of a cluster randomized controlled trial which was registered with ISRCTN.com (identifier: ISRCTN68413407) on 17 September 2013.

The authors gratefully acknowledge the women and children who participated in the Karnataka Anaemia Project 2 study.

\section{Funding}

The study was funded by the Wellcome Trust/DBT India Alliance through a Senior Fellowship Award to Dr. Arun Shet [grant reference number IA/SF/2013/AS/1].

\section{References}

1. FAO, IFAD, UNICEF $W$ and $W$. The state of food security and nutrition in the world. 1-109 p.

2. WHO. Haemoglobin concentrations for the diagnosis of anaemia and assessment of severity. Geneva 2011.

3. McLean E, Cogswell M, Egli I, Wojdyla D, de Benoist B. Worldwide prevalence of anaemia, WHO Vitamin and Mineral Nutrition Information System, 1993-2005. Public Heal Nutr. 2009;12(4):444-454.

4. Who. Serum ferritin concentrations for the assessment of iron status and iron deficiency in populations. Vitamin and Mineral Nutrition Information System. In: Who p1-5.

5. Mwangi MN, Maskey S, Andang o PEA, et al. Diagnostic utility of zinc protoporphyrin to detect iron deficiency in Kenyan pregnant women. BMC Med. 2014; 12(1):229.

6. Yu KH. Effectiveness of zinc protoporphyrin/heme ratio for screening iron deficiency in preschool-aged children. Nutr Res Pract. 2011:5(1):40-45.

7. Pasricha S-R, Atkinson SH, Armitage AE, et al. Expression of the iron hormone hepcidin distinguishes different types of anemia in African children. Sci Transl Med. 2014;6 (235):235re3:1-7.

8. Prentice AM, Doherty CP, Abrams SA, et al. Hepcidin is the major predictor of erythrocyte iron incorporation in anemic African children. Blood. 2012;119(8):1922-1928.

9. Kassebaum NJ, Jasrasaria R, Naghavi M, et al. A systematic analysis of global anemia burden from 1990 to 2010. Blood. 2014; 123(5):615-624

10. Urbaniak GC PS. Research Randomizer v4.0.

11. Weiss G, Goodnough LT. Anemia of chronic disease. N Engl J Med. 2005; 352(10):10111023.

12. Camaschella C. Iron-Deficiency Anemia. N Engl J Med. 2015;372(19):1832-1843.

13. Suominen P, Punnonen K, Rajamäki a, Irjala $K$. Serum transferrin receptor and transferrin receptor-ferritin index identify healthy subjects with subclinical iron deficits. Blood. 1998;92(8):2934-2939.

14. Deeks JJ, Altman DG. Diagnostic tests 4: likelihood ratios. BMJ. 2004;329(7458): 168-169.
15. Soldin OP, Miller M, Soldin SJ. Pediatric reference ranges for zinc protoporphyrin. Clin Biochem. 2003;36(1):21-25

16. Crowell R, Ferris AM, Wood RJ, Joyce P, Slivka H. Comparative effectiveness of zinc protoporphyrin and hemoglobin concentrations in identifying iron deficiency in a group of low-income, preschool-aged children: practical implications of recent illness. Pediatrics. 2006;118(1):224-232.

17. Abioye AI, Aboud S, Premji Z, et al. Iron supplementation affects hematologic biomarker concentrations and pregnancy outcomes among iron-deficient Tanzanian women. J Nutr. 2016;146(6):1162-1171.

18. Mohanty D, Mukherjee MB, Colah RB, et al Iron deficiency anaemia in sickle cell disorders in India. Indian J Med Res. 2008; 127(4):366-369.

19. Labbe RF. Clinical utility of zinc protoporphyrin. Clin Chem. 1992;38(11):2167-2168.

20. Sdogou T, Tsentidis C, Gourgiotis D, et al. Immunoassay-based serum hepcidin reference range measurements in healthy children : differences among age groups. J Clin Lab Anal. 2015;29(1):10-14

21. Cangemi G, Pistorio A, Miano M, et al. Diagnostic potential of hepcidin testing in pediatrics. Eur J Haematol. 2013;90(4):323 330.

22. Bhatia P, Marathe R, Hegde A, Bhardwaj D, Jain R. Plasma hepcidin levels in healthy children from Chandigarh, Northern India. Indian Pediatr. 2017:54(7):599-600.

23. Jaeggi T, Moretti D, Kvalsvig J, et al. Iron status and systemic inflammation, but not gut inflammation, strongly predict gender-specific concentrations of serum hepcidin in infants in rural Kenya. PLoS One. 2013:8(2):e57513

24. Mupfudze TG, Stoltzfus RJ, Rukobo S, Moulton LH, Humphrey JH, Prendergast AJ. Hepcidin decreases over the first year of life in healthy African infants. Br J Haematol. 2014:164(1):150-153.

25. Choi HS, Song SH, Lee JH, Kim H-J, Yang HR. Serum hepcidin levels and iron parameters in children with iron deficiency. Korean J Hematol. 2012;47286-92.

26. Ganz T, Olbina G, Girelli D, Nemeth E, Westerman M. Immunoassay for human serum hepcidin Immunoassay for human serum hepcidin. Blood. 2008; 112(10): 4292-4297.
27. Galesloot TE, Vermeulen SH, GeurtsMoespot AJ, et al. Serum hepcidin: reference ranges and biochemical correlates in the general population. Blood. 2011; 117(25): 218-226.

28. Uijterschout L, Swinkels DW, Domellöf M et al. Serum hepcidin measured by immunochemical and mass-spectrometric methods and their correlation with iron status indicators in healthy children aged 0.5-3 y. Pediatr Res. 2014;76(4):409-414.

29. van Santen S, van Dongen-Lases EC, de Vegt F, et al. Hepcidin and hemoglobin content parameters in the diagnosis of iron deficiency in rheumatoid arthritis patients with anemia. Arthritis Rheum. 2011; 63(12):3672-3680.

30. Zimmermann MB, Molinari L, StaubliAsobayire F, et al. Serum transferrin receptor and zinc protoporphyrin as indicators of iron status in African children. Am J Clin Nutr. 2005;81(3):615-623.

31. Teshome EM, Prentice AM, Demir AY, Andang'o PEA, Verhoef H. Diagnostic utility of zinc protoporphyrin to detect iron deficiency in Kenyan preschool children: a community-based survey. BMC Hematol. 2017;17(1):11

32. Serdar MA, Ümit Sarici S, Kurt I, et al. The role of erythrocyte protoporphyrin in the diagnosis of iron deficiency anemia of children. J Trop Pediatr. 2000;46(6):323-326.

33. Graham EA, Felgenhauer J, Detter IC, Labbe RF. Elevated zinc protoporphyrin associated with thalassemia trait and hemoglobin E. J Pediatr. 1996;129(1):105-110.

34. Hayden SR, Brown MD. Likelihood ratio: powerful tool for incorporating the results of a diagnostic test into clinical decisionmaking. Ann Emerg Med. 1999;33(5):575-580.

35. McGee S. Simplifying likelihood ratios. Gen Intern Med. 2002:17(8):647-650.

36. Kroot JJC, van Herwaarden AE, Tjalsma $\mathrm{H}$, Jansen RTP, Hendriks JCM, Swinkels DW. Second round robin for plasma hepcidin methods: First steps toward harmonization. Am J Hemato.1 2012;87(10):977-983.

37. WHO. Iron deficiency anaemia: assessment prevention, and control. A guide for programme managers. World Heal Organ. 2001;114

38. Bossuyt PM, Reitsma JB, Bruns DE, et al Towards complete and,accurate reporting of studies of diagnostic accuracy: the STARD initiative. Br Med J. 2003; 326(7379):41-44. 